\title{
Erratum to: Do parental traumatic experiences have a role in the psychological functioning of early adolescents with binge eating disorder?
}

\author{
Luca Cerniglia $^{1} \cdot$ Silvia Cimino $^{2} \cdot$ Giulia Ballarotto $^{2} \cdot$ Renata Tambelli $^{2}$
}

Published online: 27 February 2017

(C) Springer International Publishing Switzerland 2017

Erratum to: Eat Weight Disord (2016) 21:635-644

DOI 10.1007/s40519-016-0303-7

Unfortunately, one of the authors' first name and family name were interchanged and published in the original version of this article. The complete correct version of the authors' names is given below:

Luca Cerniglia.

Silvia Cimino.

Giulia Ballarotto.

Renata Tambelli.

The online version of the original article can be found under doi:10.1007/s40519-016-0303-7.

Luca Cerniglia

1.cerniglia@uninettunouniversity.net

1 Uninettuno International Telematic University, Corso

Vittorio Emanuele II, 39, Rome, Italy

2 Sapienza, University of Rome, Rome, Italy 